\title{
Identificação e classificação de áreas de risco em espaços urbanos da Zona Sul de Teófilo Otoni
}

\author{
Identification and classification of risk areas in urban spaces in the South Zone of Teófillo Otoni \\ Identificación y clasificación de áreas de riesgo en espacios urbanos de la Zona Sur de Teófilo Otoni
}

Recebido: 03/11/2021 | Revisado: 10/11/2021 | Aceito: 16/11/2021 | Publicado: 18/11/2021

\author{
Luély Souza Guimarães \\ ORCID: https://orcid.org/0000-0001-8817-7326 \\ Universidade Federal dos Vales do Jequitinhonha e Mucuri, Brasil \\ E-mail: luelyguimaraes@ hotmail.com \\ Antônio Jorge de Lima Gomes \\ ORCID: https://orcid.org/0000-0001-9560-6213 \\ Universidade Federal dos Vales do Jequitinhonha e Mucuri, Brasil \\ E-mail: antonio.gomes@ufvjm.edu.br \\ Jorge Luiz dos Santos Gomes \\ ORCID: https://orcid.org/0000-0002-1143-0001 \\ Universidade Federal dos Vales do Jequitinhonha e Mucuri, Brasil \\ E-mail: antonio.gomes@ufvjm.edu.br
}

\begin{abstract}
Resumo
O processo de urbanização das cidades do Brasil, em geral, foi influenciado por fenômenos econômicos que, em decorrência, promoveram uma urbanização desenfreada e sem planejamento prévio, em que inúmeras residências no território brasileiro foram desenvolvidas em locais que não se enquadravam nas características de moradia segura, nesse contexto, enquadra-se a zona sul da cidade de Teófilo Otoni em Minas Gerais. A insegurança das moradias em risco é potencializada por fenômenos hidrogeomorfológicos que, em sua maioria, estão localizados em regiões onde a topografia é desfavorável ao desenvolvimento urbano. Os riscos associados às áreas de risco são classificados em 4 estágios crescentes de agressividade, em que R1 é o risco mais leve enquanto R4 é o risco mais agressivo, e para todos os estágios existe uma medida preventiva e de proteção, por isso é importante possuir estudos ambientais direcionados a encostas, enchentes, deslizamentos e outros. Portanto, o comportamento do solo, em diferentes situações, promoverá a análise quanto à intensidade do grau de risco, além de auxiliar no processo de identificação e classificação dos tipos de lâminas a que estão sujeitas as áreas analisadas. Ressalta-se que a zona sul do município de Teófilo Otoni apresenta uma cobertura latossolo predominantemente amarelo-avermelhado, com acentuada ausência de cobertura vegetal, o que aumenta a possibilidade de riscos geológicos e ambientais.
\end{abstract}

Palavras-chave: Áreas de risco; Hidrogeomorfologia; Teófilo Otoni.

\begin{abstract}
The urbanization process of cities in Brazil, in general, was influenced by economic phenomena that, as a result, promoted an unbridled urbanization without advance planning, in which numerous homes in the Brazilian territory were developed in places that did not fit the characteristics of safe housing, in this context, the southern zone of the city of Teófilo Otoni in Minas Gerais is framed. The insecurity of housing at risk is enhanced by hydrogeomorphological phenomena that, for the most part, are located in regions where the topography is unfavorable to urban development. The risks associated with risk areas are classified into 4 increasing stages of aggressiveness, in which R1 is the mildest risk while R4 is the most aggressive risk, and for all stages there is a preventive and protective measure, and because of this it is important to have environmental studies directed at slopes, floods, landslides and others. Therefore, the behavior of the soil, in different situations, will promote the analysis as to the intensity of the degree of risk, besides helping in the process of identification and classification of the types of slides to which the analyzed areas are subjected. It is noteworthy that the southern zone of the municipality of Teófilo Otoni has a predominantly reddish-yellow latosol cover, with a marked absence of vegetation cover, which increases the possibility of geological and environmental risks.
\end{abstract}

Keywords: Risk areas; Hydrogeomorphology; Teófilo Otoni.

\section{Resumen}

El proceso de urbanización de las ciudades en Brasil, en general, fue influenciado por fenómenos económicos que, como resultado, promovieron una urbanización desenfrenada sin planificación previa, en la que se desarrollaron numerosas viviendas en el territorio brasileño en lugares que no se ajustaban a las características de seguridad. Vivienda, en este contexto, se enmarca la zona sur de la ciudad de Teófilo Otoni en Minas Gerais. La inseguridad de las viviendas en riesgo se ve reforzada por los fenómenos hidrogeomorfológicos que, en su mayor parte, se ubican en 
regiones donde la topografía es desfavorable para el desarrollo urbano. Los riesgos asociados a las áreas de riesgo se clasifican en 4 etapas crecientes de agresividad, en las que R1 es el riesgo más leve mientras que R4 es el riesgo más agresivo, y para todas las etapas existe una medida preventiva y protectora, por lo que es importante Contamos con estudios ambientales dirigidos a pendientes, inundaciones, deslizamientos de tierra y otros. Por tanto, el comportamiento del suelo, en diferentes situaciones, promoverá el análisis en cuanto a la intensidad del grado de riesgo, además de ayudar en el proceso de identificación y clasificación de los tipos de deslizamientos a los que están sometidas las áreas analizadas. Es de destacar que la zona sur del municipio de Teófilo Otoni tiene una cubierta de latosol predominantemente de color amarillo rojizo, con una marcada ausencia de cobertura vegetal, lo que aumenta la posibilidad de riesgos geológicos y ambientales.

Palabras clave: Áreas de riesgo; Hidrogeomorfología; Teófilo Otoni.

\section{Introdução}

Desde a antiguidade o solo e a água são elementos de manutenção da vida em sociedade. Tal fato se comprova, historicamente, devido a necessidade dos primórdios em reunir grupos de indivíduos ao redor de rios e solos férteis, o que garantia boa qualidade de vida e manutenção (Almeida e Carvalho, 2010).

Em Teófilo Otoni - MG, esse contexto não foi diferente, a cidade teve seu crescimento ao redor do Rio Todos os Santos que corta a região central, e a partir disso o ambiente foi se modificando e se concretizando como uma cidade de médio porte, no qual não possui relações hierárquicas com outros espaços urbanos, cujo o processo evolutivo é autônomo (Almeida e Carvalho, 2010; Batella, 2018).

O crescimento urbano desordenado dos últimos anos de Teófilo Otoni contribuiu para o aumento das áreas de risco ambiental e geológico, tornando a prevenção de desastres e acidentes um dos grandes desafios a serem enfrentados pelo poder público e pela sociedade (Ramos e Gomes, 2016).

O quadro topográfico que originou a cidade de Teófilo Otoni apresenta uma área territorial que se caracteriza pela presença de morros com encostas de fortes declividades nas porções norte, noroeste, oeste, sudoeste, sudeste, nordeste e também na zona sul da cidade, que será o objeto de estudo. Por outro lado, as áreas centrais apresentam topografias que oferecem menores declividades e, por conseguinte, menores limites para sua ocupação (Batella, 2018).

A composição e as características espaciais do solo influenciam significativamente em como este se comporta diante das interferências diretas e indiretas, como por exemplo o tipo de solo de uma determinada região e a influência das precipitações sobre ele, respectivamente, podem auxiliar nos movimentos de massas. Os fatores que podem contribuir ou facilitar para a ocorrência do deslocamento de massa de solo estão associados a declividade e a profundidade, o que reduz o fator de segurança no caso de uma encosta, por exemplo (Zêzere, 2005; Tominaga, 2009).

O desenvolvimento industrial e tecnológico possui diversas influências com relação a ocupação do solo por indivíduos. Em consequência disso, a forma como o território é ocupado pela população se baseia em diversos critérios como, por exemplo, o tamanho do mercado local, a infraestrutura urbana, a concentração de atividades, sendo que em geral o âmbito econômico é o fator determinante (Andrade, 2015).

Para que seja eficiente e executado com exatidão, é necessário que o planejamento territorial seja embasado no mapeamento geológico local, sendo necessária a avaliação de alguns fatores, como as peculiaridades gerais e específicas da região, o processo de ocupação, as práticas inadequadas do uso do solo que influenciam na ocorrência de desastres, as técnicas construtivas indevidas, as intervenções inadequadas em antigas áreas de exploração, a deficiência na oferta de terras para o desenvolvimento formal em contraste com a necessidade por moradias populares. Além disso, com relação às cidades que tiveram um processo desordenado de urbanização, como também as que não se enquadram neste cenário e possuem bairros definitivamente vigentes, esses podem estar expostos às ameaças naturais, visto que os projetos das cidades não possuem o comportamento do ambiente físico instaurado (Vargas e Cortés, 2009; Bertone e Marinho, 2013). 
Em virtude disso, e considerando a Zona Sul da cidade de Teófilo Otoni - MG como foco deste estudo, é válido salientar que esta se enquadra como uma cidade média por não possuir relações hierárquicas com outros espaços urbanos, cujo o processo evolutivo é autônomo. De maneira geral, a cidade possui crescimento desenfreado e sem planejamento urbano adequado, o que resulta em áreas de risco, que em sua maioria tem como causa ações antrópicas. É válido ressaltar que, por ser um solo do tipo latossolo vermelho-amarelo, promove instabilidade (Batella, 2018; Gomes, 2020).

A cidade de Teófilo Otoni possui grande quantidade de áreas que se enquadram em situações de risco, visto que parte dessas áreas se encontram urbanizadas. Estes problemas são desafiadores para os órgãos públicos, considerando que tais situações são agravadas pela da falta de prioridade dos gestores, que consequentemente não primaziam as demandas sociais que estão associadas ao meio ambiente, como também a necessidade de melhores políticas públicas direcionadas aos setores socias e ambientais.

\section{1 Área de estudo}

\subsubsection{Localização}

Este estudo foi desenvolvido na Zona Sul da cidade de Teófilo Otoni, que está localizada no nordeste do estado de Minas Gerais, como apresentado na Figura 1.

De acordo o Instituto Brasileiro de Geografia e Estatística, a área territorial de Teófilo Otoni corresponde a 3.242,270 $\mathrm{km}^{2}$ e a população estimada de 140.937 habitantes, apresentando densidade demográfica de 41,56 habitantes/km² (IBGE, 2019).

A cidade possui clima tropical quente semiúmido, ou tropical com estação seca, tendo temperatura média anual de 23 ${ }^{\circ} \mathrm{C}$, com invernos secos e amenos e verões chuvosos com temperaturas elevadas (IBGE, 2018).

A morfologia de Teófilo Otoni se caracteriza por ser composta por planaltos de profunda dissecação fluvial e clima que apresenta pluviosidade concentrada na estação chuvosa, entre os meses de outubro a março, período em que ocorrem altos índices pluviométricos anuais, sendo superiores a 80\% (Ferraz et al., 2016).

Na Figura 1 apresenta-se a localização do Município de Teófilo Otoni no Estado de Minas Gerais.

Figura 1: Localização da cidade de Teófilo Otoni - MG.

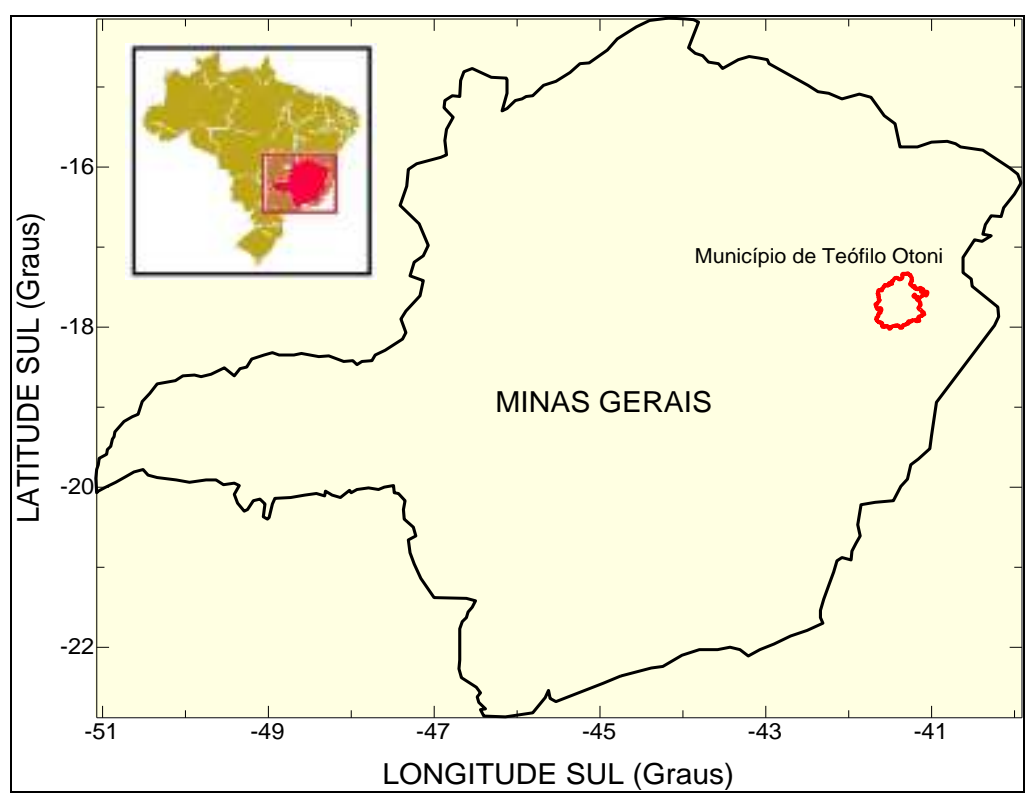

Fonte: Gomes (2012). 


\subsubsection{Geologia Regional}

A região que abrange a cidade de Teófilo Otoni tem sua geologia com predominância pré-cambriana e a principal formação geológica pertence ao complexo Juiz de Fora. Dentro desta formação estão compreendidas as formações Tumiritinga e Tonalito São Vitor (Gomes et al., 2014).

Do ponto de vista pedológico a cidade de Teófilo Otoni apresenta predominância de latossolos vermelho-amarelos e vermelhos nos terços superiores das vertentes e nos topos. Nas feições de maior declividade dão lugar aos argissolos e cambissolos, vermelhos e vermelho-amarelos.

$\mathrm{Na}$ maioria das vezes as vertentes destas feições apresentam afloramentos rochosos ou cicatrizes de escorregamentos. Com relação a estrutura litológica da região, esta é composta por rochas arqueano-proterozóicas de variado grau metamórfico, principalmente por tonalitos, xistos e gnaisses, estruturalmente afetados por falhas e lineamentos de direção principal NE-SW (Ferraz et al., 2016).

Com base na análise da folha SE.24-V-C-IV - Teófilo Otoni, descrita no Projeto Leste (CPRM, 1996) é possível verificar o recorte de formação geológico de Teófilo Otoni, no qual é feito um levantamento geológico básico do Brasil nas regiões que compreendem desde a Serra do Espinhaço à divisa do Espírito Santo e Bahia. Esse recorte descreve as formações geológicas existentes e os respectivos períodos e eras de formação que seguem apresentados nas Figuras 2 e 3.

As figuras 2 e 3 apresentam as duas formações geológicas que predominam na região da cidade de Teófilo Otoni, sendo estas a formação Tumiritinga e o Tonalito São Vitor, que foram formadas no período neoproterozóico.

Figura 2: Formações geológicas da região de Teófilo Otoni-MG.

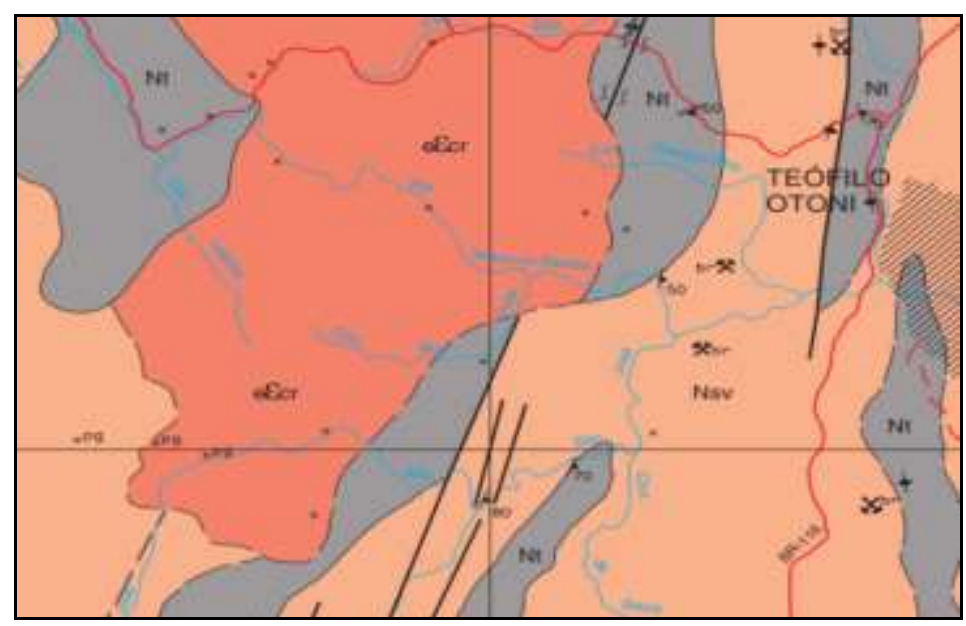

Fonte: Adaptado de CPRM (1996). 
Figura 3: Descrição das formações geológicas.

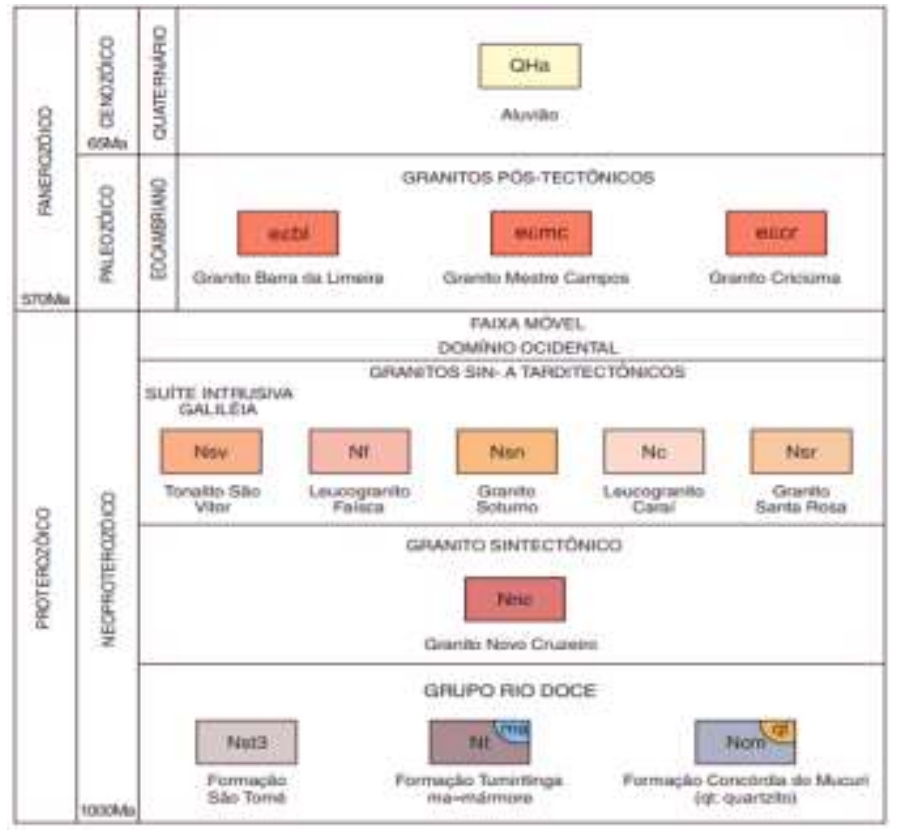

Fonte: Adaptado de CPRM (1996).

A formação Tumiritinga se apresenta dentro da classe dos granitos sintectônicos no grupo Rio Doce e é caracterizada pela presença de Biotita gnaisse xistoso, cinza, ocasionalmente com cordierita, sillimanita e granada, por vezes migmatizado, com calcissilicática e biotita xisto intercalados, ocorre a presença de mármore (ma) localmente (CPRM, 1996).

O Tonalito São Vitor se apresenta dentro da classe de granitos sin-a tarditectônicos na suíte intrusiva Galiléia e é caracterizado pela presença de Biotita tonalito, hornblenda-biotita tonalito e, subordinadamente, biotita granodiorito, de cor cinza, granulação varia de média a grossa, foliado e com megacristais de feldspato com textura de fluxo magmático (CPRM, 1996).

\section{Referencial Teórico}

Hodiernamente, inúmeras definições abrangem a palavra solo, sendo que estas se baseiam na evolução, na gênese e nas propriedades, como também no referencial de utilização e aplicação deste, o que promove um direcionamento do estudo. A definição declarada pelo Sistema Brasileiro de Classificação de Solos - SiBCS (EMBRAPA, 2018), de abrangência nacional, apresenta que o solo é um aglomerado de corpos naturais, tridimensionais, dinâmicos, composto por partes sólidas, líquidas e gasosas, sendo constituído por minerais e materiais orgânicos. Este é dividido em horizontes ou camadas que se diferem pela sua composição atrelada a compostos que podem possuir ou não vida, vinculado ao tempo, além de estar suscetível a comutações provindas da ação humana.

Salienta-se que o conceito direcionado a função do solo é preciso, sendo que se evidencia na produção de biomassa, no armazenamento, na filtragem e transformação de nutrientes, substâncias e água, além de fornecer e se manter como uma base física e cultural para o homem e suas atividades, o fornecimento de habitats, ademais de funcionar como fonte de matériaprima, arquivos geológicos e arqueológicos (Paul et al., 2020). 


\subsection{Movimentos de massa}

Brasil (2007) apresenta que o movimento do solo se define como o deslocamento de solos, rochas ou detritos, ocasionado pela ação da gravidade, em terrenos inclinados, tendo como fator principal a infiltração de água, em especial, as pluviais. Esse processo é conhecido como escorregamento e deslizamento, e pode ser causado por ações antrópicas ou naturais.

Quando relacionados a ações antrópicas, esses movimentos podem ocorrer a partir da modificação da estrutura ambiental, principalmente no que se refere à modificação do relevo através de cortes no solo e ocupação desornada, visto que ambos estão associados a um não planejamento (Brasil, 2007).

$\mathrm{Na}$ literatura a classificação ou tipologia dos movimentos de massa divide opiniões, diante disso para esse estudo a classificação dos movimentos foi embasada no Mapeamento de Riscos em Encostas e Margem de Rios - IPT (Brasil, 2007), que teve como suporte a literatura do Augusto Filho (1992), que é uma das bibliografias com maior respaldo nas pesquisas geomorfológicas brasileiras.

Diante as considerações acima apresentadas, é importante considerar os movimentos de massa. Estes se dividem em quatro tipos e se baseiam em fatores semelhantes, contudo em exposição e intensidades distintas. Eles serão abordados nos subtópicos a seguir.

\subsubsection{Rastejo}

O rastejamento é o tipo de movimento de massa que se caracteriza por possuir movimentos lentos e que englobam grandes massas de materiais, sendo que a velocidade com que ele ocorre gira em torno de milímetros e/ou centímetros ao ano ( $\mathrm{mm} / \mathrm{ano}$ e/ou $\mathrm{cm} / \mathrm{ano}$ ). Evidencia-se que a principal causa antrópica é a execução de cortes na extremidade média inferior de uma encosta, o que indica a instabilidade. Esse tipo de movimento é predominante em horizontes superficiais do solo, na camada de transição do solo e da rocha, como também na própria rocha; não apresenta um perfil de ruptura definido, e as evidências que indicam a ocorrência desse movimento se baseiam em trincas que evoluem drasticamente pela extensão das áreas, além de árvores, postes e outros que indicam as variações com relação a inclinação (BRASIL, 2007).

\subsubsection{Deslizamento}

O Ministério das Cidades (Brasil, 2007) caracteriza os deslizamentos como sendo mais rápidos que os rastejamentos, com velocidade média medida em metros por hora ou segundo $(\mathrm{m} / \mathrm{h}$ e/ou $\mathrm{m} / \mathrm{s})$, conforme as características da área, e podem se originar a partir de ações naturais ou antrópicas. Esse tipo de movimento possui limites laterais e profundidade bem definidos, pode abranger saprolito, rocha e depósitos, e possui as águas pluviais como o fator determinante para sua ocorrência. Os deslizamentos são divididos em planares ou translacionais, circulares ou rotacionais, sendo que esta classificação varia de acordo a função do mecanismo de ruptura, geometria e material que foi mobilizado. O manual supramencionado os define como:

Planar: ocorre predominantemente em solos pouco desenvolvidos e com altas declividades e em solos saprolíticos, saprolitos e rocha, condicionados por um plano de fraqueza desfavorável à estabilidade, relacionado a estruturas geológicas diversas (foliação, xistosidade, fraturas, falhas, etc.).

Circulares ou rotacionais: a superfície de deslizamento é curva, na qual é comum a ocorrência de rupturas combinadas e sucessivas, associadas a aterros, pacotes de solo ou depósitos mais espessos, rochas sedimentares ou cristalinas intensamente fraturadas.

Cunha: estão associados a processos naturais como a erosão, e ocorrem com predominância em taludes de corte e encostas. Se baseiam onde ocorre a existência de dois planos de fraqueza desfavoráveis à estabilidade, condicionando-os ao deslocamento ao longo do eixo de intersecção destes planos, como os saprolitos e maciços rochosos. 


\subsubsection{Quedas}

Esses movimentos são extremamente rápidos, com velocidade medida em metros por segundo $(\mathrm{m} / \mathrm{s})$ e englobam blocos e/ou lascas de rocha em movimento de queda livre, instabilizando um volume de rocha relativamente pequeno.

Esse processo está associado a afloramentos rochosos que podem gerar tombamentos e rolamentos. Os tombamentos são movimentos mais lentos que as quedas e ocorrem principalmente em taludes de corte, onde a mudança da geometria acaba desconfinando estas descontinuidades, propiciando o tombamento das paredes do talude. Os rolamentos, por sua vez, ocorrem naturalmente quando os processos erosivos removem o apoio da base de uma encosta. As causas deste processo se baseiam na presença de descontinuidades no maciço rochoso, na subpressão por meio do acúmulo de água, ou na penetração de raízes (Brasil, 2007).

\subsubsection{Corridas}

Esse tipo de movimento de massa ocorre devido a fatores pluviométricos e é mais raro que os deslizamentos, visto que ocorre a partir de deslizamentos nas encostas e mobiliza grandes volumes de material; o escoamento se dá ao longo de um ou mais canais de drenagem, tendo comportamento fluído aderente e com alto poder de transporte e destruição. Logo, a fim evidenciar as características desses processos, segue o quadro referente a classificação dos tipos de movimento de massa (Brasil, 2007).

\subsection{Tipos de Muros de Contenção}

Estruturas de contenção tem o objetivo de se opor a tensões provocadas em um maciço cuja condição de equilíbrio foi alterada. Nesse contexto, os muros podem se dividir em dois grupos, sendo o primeiro conhecido como muro de peso ou de gravidade que podem ser construídos de alvenaria de pedras, concreto ciclópico, gabiões, solo-cimento ou solo reforçado. O segundo grupo são muros de flexão que são de concreto armado e podem ser com ou sem contraforte e com ou sem ancoragens.

\subsubsection{Muros de peso ou gravidade}

Se caracterizam por serem muros que contrapõem ao empuxo horizontal utilizando o próprio peso e os esforços da base, que garantem estabilidade.

\subsubsection{Muros de alvenaria em pedras}

Consiste num muro de pedras confeccionado manualmente. A resistência do muro é resultado do embricamento dos blocos de pedras, e possui como vantagem o baixo custo, a simplicidade de construção e a ausência de dispositivos de drenagem, visto que o material do muro é drenante (Gerscovich, 2007).

Sua execução é simples e seu uso é normalmente empregado para muro de até $2 \mathrm{~m}$ de altura. Caso ultrapasse essa grandeza, é necessária a utilização de argamassa a fim de possibilitar alturas elevadas, contudo, deve-se considerar a perda da característica drenante, visto que a argamassa irá preencher os espaços vazios, sendo assim, indispensável pensar a utilização de outros dispositivos drenantes (Gerscovich, 2007).

\subsubsection{Muros de gabiões}

Esses muros são gaiolas metálicas organizadas manualmente e preenchidas de pedras naturais. Salienta-se que o diâmetro das pedras deve ser entre 1 e 2 vezes maior que a malha de aço. A face do muro é drenante devido a não utilização da argamassa, contudo, é importante o uso de geotexil associado a uma camada granular junto ao tardoz para evitar o carreamento dos grãos finos do solo (Gerscovich, 2007). 


\subsubsection{Muros de concreto ciclópico}

É uma estrutura construída por meio do preenchimento de uma fôrma com concreto e blocos de rocha de dimensões distintas. É um muro indicado para pequenas alturas e sua seção transversal é normalmente trapezoidal. Por ser um muro que possui alto teor de impermeabilidade é indispensável, salienta-se ainda, que os furos de drenagem devem ser alocados de maneira a atenuar o impacto visual das manchas que é provocado pelo fluxo de água na fachada do muro (Gerscovich, 2007).

\subsubsection{Muros de sacos de solo-cimento}

Este tipo de contenção é constituída de sacos preenchidos por solo e cimento, dispostos em camadas. Sua maior vantagem é sua facilidade de adaptação à topografia do local, além de ser de fácil execução. De maneira geral, os muros são constituídos por camadas formadas por sacos de poliéster ou similares, preenchidos por uma mistura cimento-solo da ordem de 1:10 a 1:15, em volume. O benefício desse muro está associado a facilidade de execução do muro com forma curva (adaptada a topografia local) e a adequabilidade do uso de solos residuais (Gerscovich, 2007).

\subsubsection{Muros de solo reforçado}

Esse muro se caracteriza por alcançar grandes alturas e se baseiam na utilização de solo reforçado que são realizados por meio da compactação do solo com algum elemento de reforço, o que garante maior desempenho mecânico ao solo. Sua vantagem é a facilidade com relação a execução, pois não necessita de mão de obra especializada (Gerscovich, 2007).

\subsubsection{Muros de flexão em concreto armado}

Esse tipo de muro é feito de concreto armado com o objetivo de resistir à esforços de flexão provocados pelo empuxo. É possível alcançar alturas elevadas com esse tipo de muro por meio da utilização do contraforte que possibilita um melhor desempenho estrutural diminuindo a espessura da parede (Gerscovich, 2007).

\subsubsection{Solo grampeado}

É um muro feito através de grampos fixados no terreno, resistentes à flexão composta, reduzindo a deformação do solo. Os grampus são componentes que são acionados somente quando solicitado, ou seja, quando o solo sofre alguma alteração, sendo no projeto considerado sua resistência a tração e em alguns casos sua resistência ao cisalhamento (Gerscovich, 2007).

Salienta-se que a execução é realizada por meio da escavação em etapas, sendo que em cada etapa a espessura do solo é de aproximadamente de 1 a $2 \mathrm{~m}$, e posteriormente é alocado o grampo. É necessário que antes da perfuração, os grampos recebam tratamento anticorrosivo (Gerscovich, 2007).

\subsubsection{Cortina ancorada}

A cortina ancorada é um muro que permite a contenção através de paredes verticais ou subverticais de concreto armado com ancoragens fixadas no terreno. A ancoragem é composta por calda de cimento e barra de aço e pode ser dividido em dois trechos, o ancorado e o livre, sendo que trecho ancorado distribui a carga de tração ao terreno através da calda de cimento e o trecho livre distribui a carga de tração entre a cabeça da ancoragem e o trecho ancorado. As paredes apresentam espessura entre 20 e $40 \mathrm{~cm}$, sendo está definida através do espaçamento entre as ancoragens e das cargas solicitadas (Gerscovich, 2007). 


\section{Metodologia}

As metodologias empregadas se baseiam em métodos exploratórios, quantitativos e qualitativos, de maneira geral, por meio de revisões bibliográficas e visitas de campo que permitiram a análise do local para que haja o entendimento do comportamento do solo nas diversas situações analisadas, o que permite a extração de informações que auxiliam na compreensão da pesquisa.

Inicialmente, está se baseará em identificar a distribuição do solo dos locais em estudo, visto que serão analisadas as diferentes áreas da cidade de Teófilo Otoni - MG, ou seja, identificar as formas de uso deste solo, que pode ser uma área predominantemente edificada, vegetada, entre outras. Almeida e Freitas (1996) apresentam as formas de utilização do solo em áreas urbanas, conforme especificado no Quadro 1.

A classificação do tipo de risco dos locais com relação consistirá na análise das áreas, com o objetivo de identificar em qual grau elas se encaixam, dessa maneira, apresentamos no Quadro 2 os graus de risco com relação aos escorregamentos e às respectivas condições preestabelecidas.

Quadro 1: Formas de uso do solo e suas características.

\begin{tabular}{|c|c|}
\hline Formas de uso do solo & Características \\
\hline Cobertura vegetal (mata) & $\begin{array}{l}\text { Inclui áreas cobertas principalmente por mata e capoeira. Nas áreas } \\
\text { urbanas encontram-se em áreas restritas, onde o relevo é mais enérgico, } \\
\text { ou nas áreas de preservação. }\end{array}$ \\
\hline Reflorestamento & $\begin{array}{l}\text { Áreas de recomposição da cobertura vegetal, em sua maioria para fins } \\
\text { econômicos. }\end{array}$ \\
\hline Campo antrópico/pastagens (interferências antrópicas) & Áreas onde predominam vegetação herbácea, com alguns ar. \\
\hline Áreas agrícolas & $\begin{array}{c}\text { Áreas destinadas a cultivos perenes ou temporários (ciclo estabelecido). } \\
\text { Nas áreas urbanas destacam-se a horticultura e as chácaras rurais (que } \\
\text { destinam parte dos lotes a pequenos cultivos). }\end{array}$ \\
\hline $\begin{array}{l}\text { Área urbana consolidada } \\
\text { (área edificada) }\end{array}$ & $\begin{array}{l}\text { Caracteriza-se por ser densamente ocupada, e pela disponibilidade de } \\
\text { infraestrutura básica e equipamentos, atividades de comércio e serviços, } \\
\text { etc. }\end{array}$ \\
\hline Área urbana em consolidação & $\begin{array}{l}\text { Constitui áreas com densidade de ocupação média/alta, apresentando } \\
\text { ainda alguns vazios urbanos, e infraestrutura e equipamentos restritos. } \\
\text { Destacam-se nessas áreas grandes loteamentos e sistemas de } \\
\text { autoconstrução. }\end{array}$ \\
\hline Área urbana parcelada & $\begin{array}{c}\text { Corresponde à ocupação periférica, de densidade média/baixa, } \\
\text { caracterizada por loteamentos em implantação, destinados à classe social } \\
\text { menos favorecida, em que há falta de infraestrutura e equipamentos } \\
\text { urbanos. }\end{array}$ \\
\hline Favelas & $\begin{array}{l}\text { Habitações precárias, instaladas ao longo dos córregos ou em encostas, } \\
\text { sem infraestrutura básica (saneamento de água, esgotos, etc.). }\end{array}$ \\
\hline Disposição de resíduos & $\begin{array}{l}\text { Locais para destinação final do lixo urbano, na forma de aterro sanitário, } \\
\text { lixão ou aterro controlado. }\end{array}$ \\
\hline
\end{tabular}

Fonte: Adaptado de Almeida e Freitas (1996). 
Quadro 2: Graus de risco de processos associados a movimentos de massa.

\begin{tabular}{|c|c|c|}
\hline Grau & Classificação & Descrição \\
\hline $\mathbf{R 1}$ & Baixo & $\begin{array}{l}\text { Não há indícios de desenvolvimento de processos destrutivos em encostas e } \\
\text { margens de drenagens. } \\
\text { Mantidas as condições existentes, não se espera a ocorrência de eventos } \\
\text { destrutivos. }\end{array}$ \\
\hline $\mathbf{R} 2$ & Médio & $\begin{array}{l}\text { Observa-se a presença de alguma(s) evidência(s) de instabilidade (encostas e } \\
\text { margens de drenagens), porém incipiente(s). } \\
\text { Mantidas as condições existentes, é reduzida a possibilidade de ocorrência de } \\
\text { eventos destrutivos durante episódios de chuvas intensas e prolongadas. }\end{array}$ \\
\hline $\mathbf{R 3}$ & Alto & $\begin{array}{l}\text { Observa-se a presença de significativa(s) evidência(s) de instabilidade (trincas no } \\
\text { solo, degraus de abatimento em taludes etc.). } \\
\text { Mantidas as condições existentes, é perfeitamente possível a ocorrência de eventos } \\
\text { destrutivos durante episódios de chuvas intensas e prolongadas. }\end{array}$ \\
\hline R4 & Muito Alto & $\begin{array}{l}\text { As evidências de instabilidade (trincas no solo, degraus de abatimento em taludes, } \\
\text { trincas em moradias ou em muros de contenção, árvores ou postes inclinados, } \\
\text { cicatrizes de escorregamento, feições erosivas, proximidade da moradia em } \\
\text { relação ao córrego etc.) são expressivas e estão presentes em grande número e/ou } \\
\text { magnitude. } \\
\text { Mantidas as condições existentes, é muito provável a ocorrência de eventos } \\
\text { destrutivos durante episódios de chuvas intensas e prolongadas. }\end{array}$ \\
\hline
\end{tabular}

Fonte: Adaptado de CPRM (2015).

As cores do quadro anterior representam uma identificação visual associada ao tipo de risco. A cor verde é caracterizada pelo Risco Baixo denominado de R1. A cor amarela indica o risco médio do tipo R2. O risco R3 é classificado como alto e indicado pela cor laranja. Já o Risco muito alto classificado como R4 é representado pela cor vermelha.

\section{Levantamento de Dados}

O levantamento dos dados compreende três áreas de estudo que estão localizadas no Bairro Jardim São Paulo, Funcionários e Vila Ramos. Estes bairros se caracterizam por estarem em sitio urbano, por possuírem escorregamentos, profundidade e alturas consideráveis, e em algumas situações solo mais arenoso e elevado grau de vegetação.

A primeira área de estudo está localizada na Rua Godofredo Mollendorff no bairro Funcionários e se caracteriza por ser uma voçoroca que foi originada por processos antrópicos, ou seja, provocados pela ação humana e sem estudos direcionados a sua manutenção e comportamento. A água que percola sobre o solo é proveniente de uma bacia hidrográfica e essa deságua no córrego São Benedito. Além disso, a área também se caracteriza por possuir um aterro de baixo porte e deslizamentos de solos provenientes da percolação da água. As imagens, Figuras 4 e 5 apresentam a áreas mencionada. 
Figura 4: Voçoroca no Bairro Funcionários.

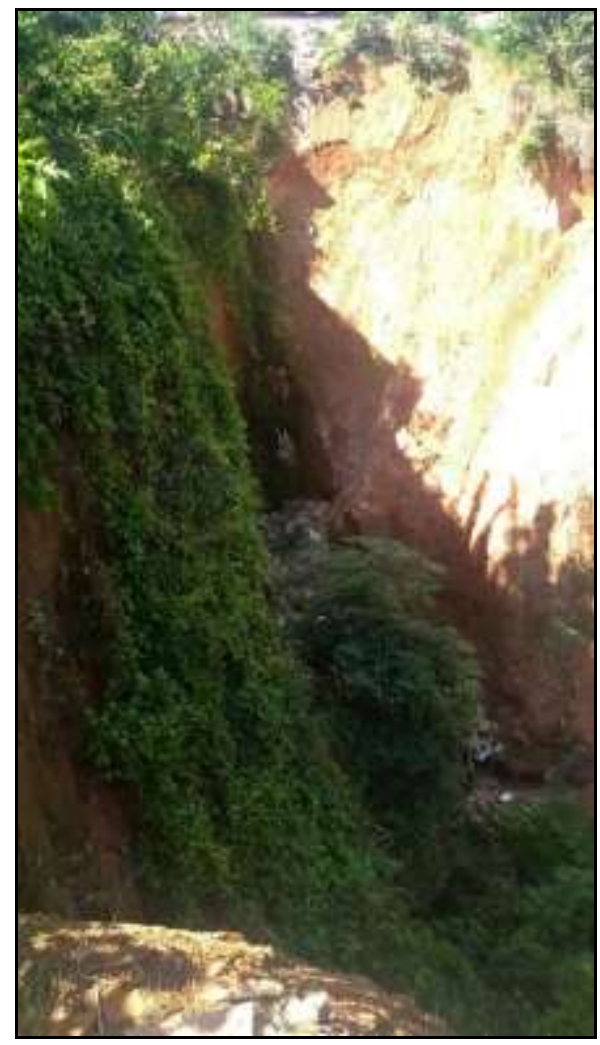

Fonte: Autores (2021).

Figura 5: Voçoroca no Bairro Funcionários.

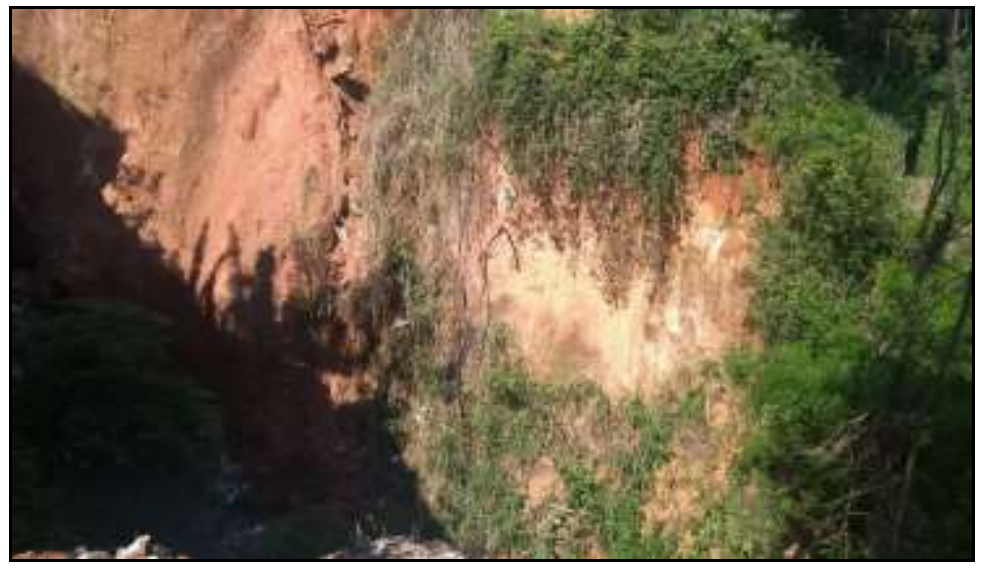

Fonte: Autores (2021).

A próxima área é localizada no Bairro Jardim São Paulo, na rua Presidente Prudente. Se caracteriza por ser uma área urbana em consolidação, que possui uma obra antiga na qual as condições não são adequadas à população, visto que já ocorreram situações indesejáveis, como deslizamentos que ocasionaram em perdas matérias. Inicialmente foi feito um muro de contenção para mudar o sentido das águas pluviais para que não alcançassem a parte inferior da encosta, objetivando a drenagem da água no interior do solo e gerando maior segurança às residências.

Contudo, principalmente em épocas chuvosas, há o aumento da instabilidade da área. Em consequência disso, ocorre ravinas que auxiliam na fragilidade, e há a presença de solo artificial superior ao solo natural. Entretanto, apesar do exposto o solo apresenta ser instável na ausência de chuvas. Ademais, salienta-se a existência de vegetação no corpo da encosta, o que garante solo orgânico e permite, minimamente, estabilidade. As imagens, Figuras 6, 7 e 8 apresentam a áreas mencionada. 
Figura 6: Área analisada no bairro Jardim São Paulo.

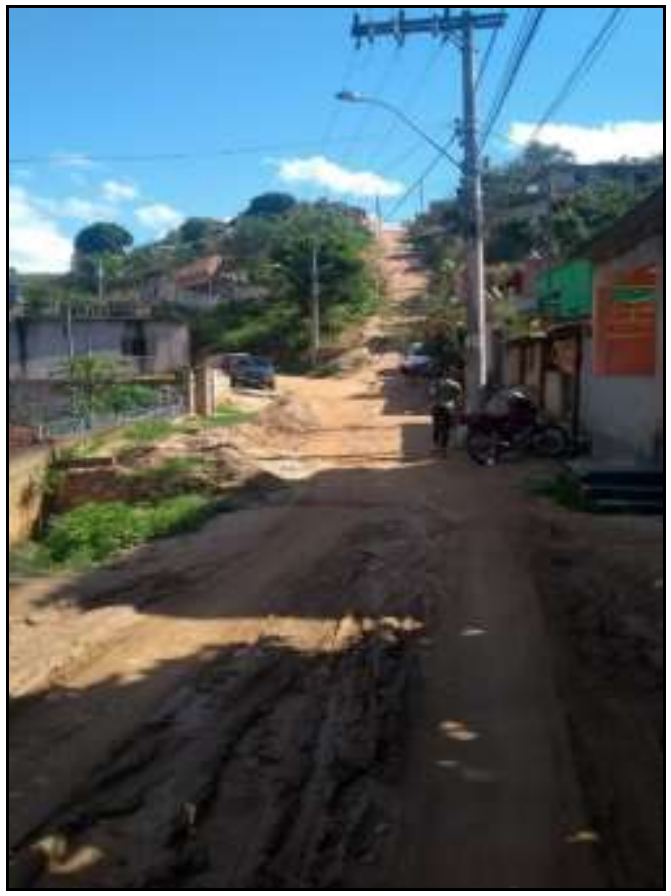

Fonte: Autores (2021).
Figura 7: Muro de saco solo-cimento.

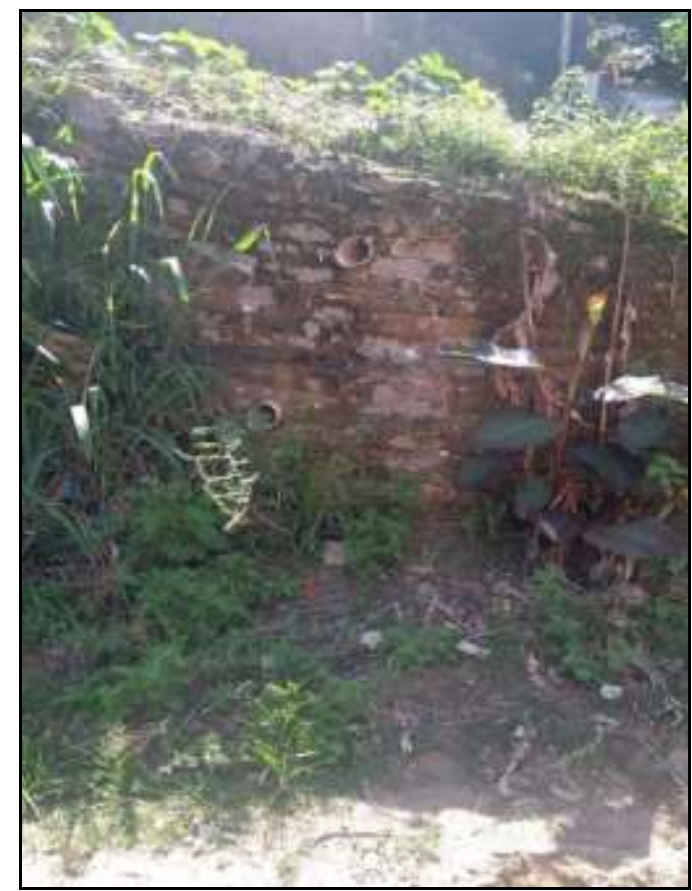

Fonte: Autores (2021).

A última área está localizada na rua Altamiro Nunes Leite no bairro Vila Barreiros, e é uma área urbana consolidada, e o local de estudo está em uma região que possui vários cortes no corpo do solo, sendo possível analisar os horizontes. Este solo se destina a base de edificações e devido a isso possui um muro de contenção, a fim de inibir o deslocamento de massa. Ainda, no corpo da encosta há a existência de um muro de cortina atirantada que possui a própria encosta como meio de sustentação, na qual agrava a situação devido a provável instabilidade dessa. De maneira geral, a área se caracteriza por ser vegeta e ser uma região de muito acesso de veículos e pedestres. As imagens, Figuras 9 e 10 apresentam a áreas mencionada. 
Research, Society and Development, v. 10, n. 15, e254101522754, 2021

(CC BY 4.0) | ISSN 2525-3409 | DOI: http://dx.doi.org/10.33448/rsd-v10i15.22754

Figura 8: Trincas em residência localizada na Encosta.

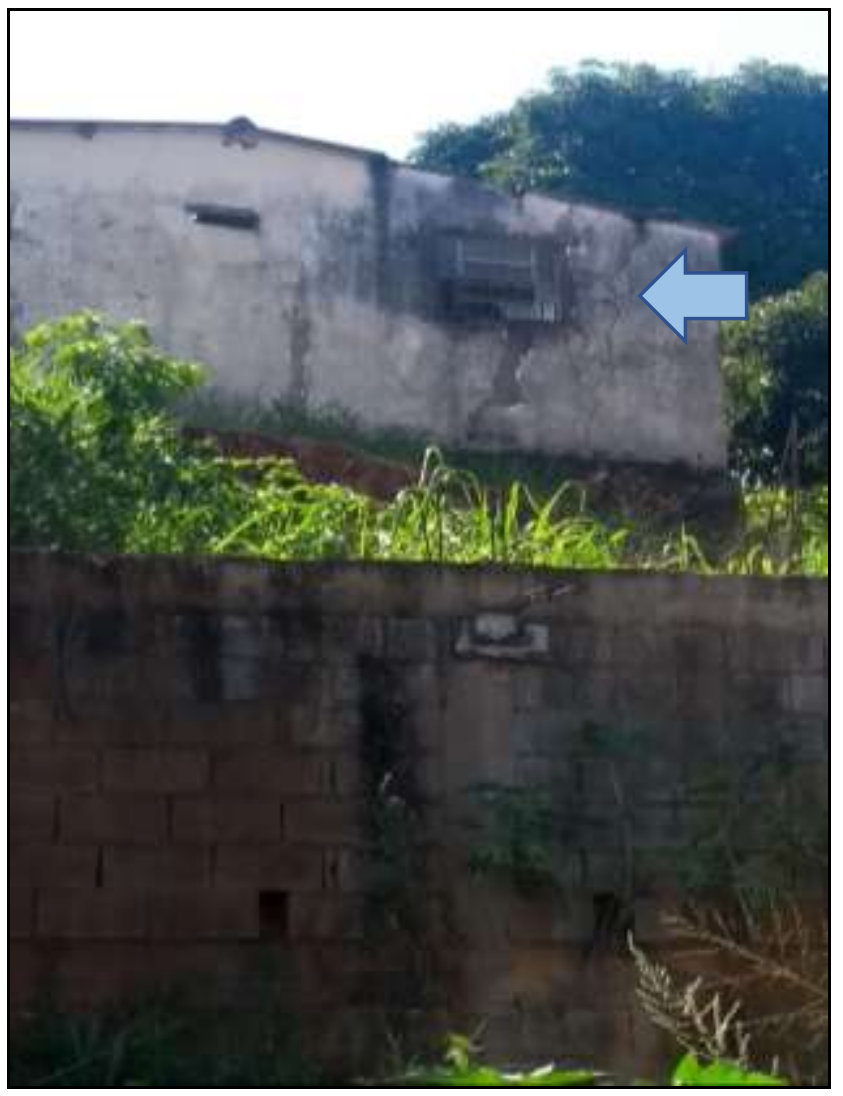

Fonte: Autores (2021).

Figura 9: Muro grampeado que não tem função estrutural do solo.

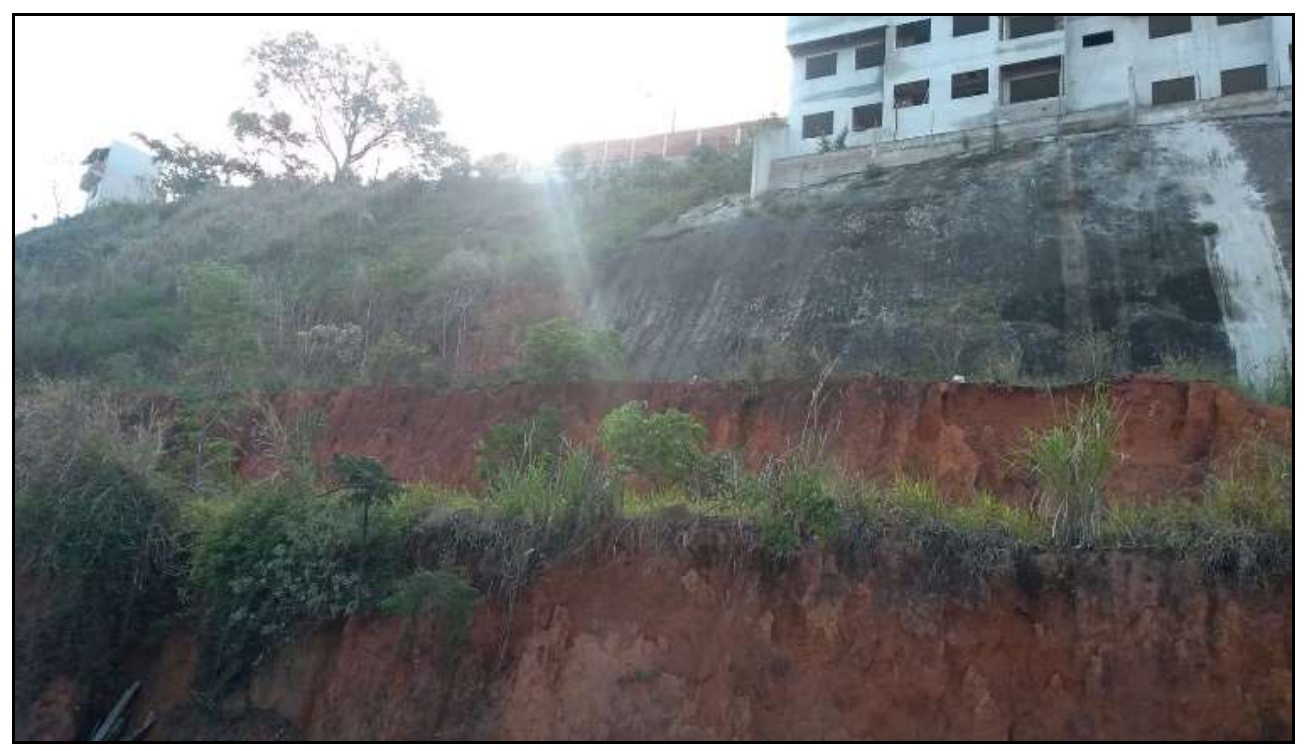

Fonte: Autores (2021). 
Figura 10: Muro grampeado que não tem função estrutural do solo de outro ângulo.

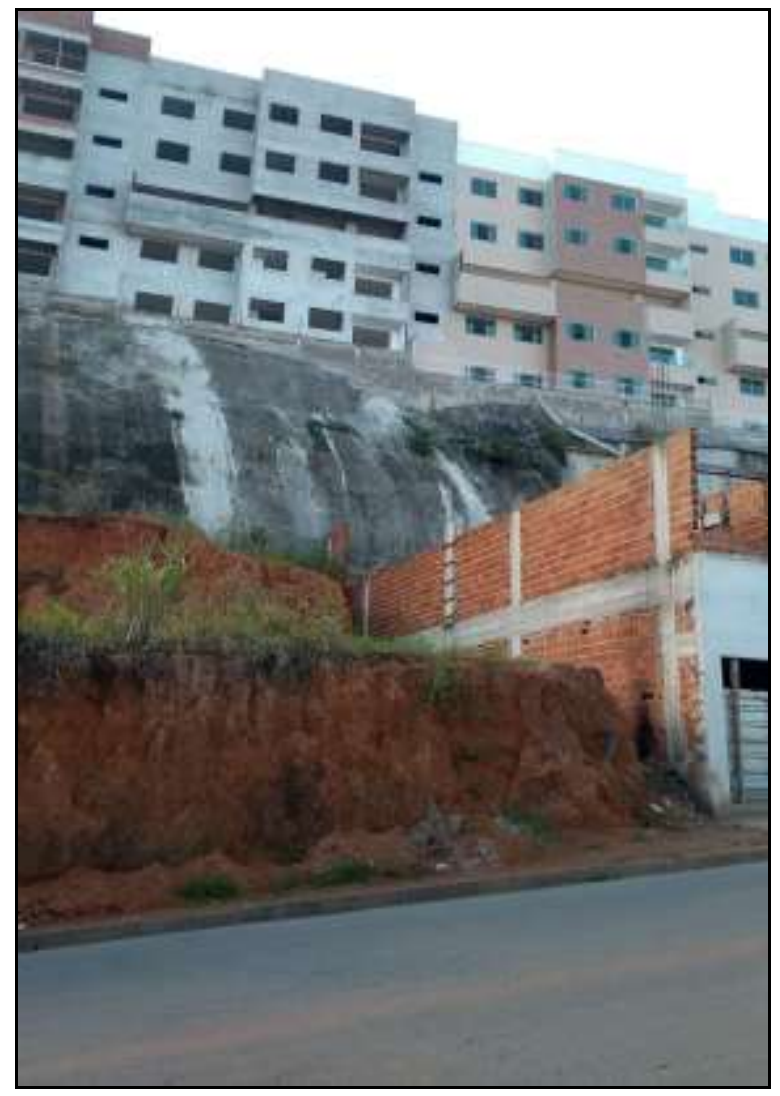

Fonte: Autores (2021).

\section{Resultados e Discussões}

A área localizada na rua Godofredo Mollendorff no bairro Funcionários se qualifica como uma área urbana parcelada, conforme a Quadro 1. Ela possui os rastejos como movimento predominante, por possuir velocidades baixas de deslizamento, sendo decrescentes com a profundidade, além de possuir movimentos constantes associados aos movimentos de águas meteóricas, vindas da sub-bacia hidrográfica local. Apesar de hodiernamente se qualificar como rastejamento, a área se enquadra a classificação R4 - Risco Muito Alto, devido ao seu histórico que já promoveu a evacuação de residências do local devido a deslizamentos, e atualmente observa-se a presença de evidências de instabilidade. Salienta-se que no segundo semestre de 2021 os órgãos públicos responsáveis de Teófilo Otoni realizaram uma obra a fim de sanar os desafios do local e acabaram com a voçoroca, contendo a erosão local, e fizeram uma área de acesso a fim de facilitar a locomoção dos moradores, no entanto após as primeiras chuvas, constatou-se que a obra não foi realizada dentro das técnicas recomendadas e já necessita de nova intervenção.

A segunda área, levantada localizada no Bairro Jardim São Paulo, na rua Presidente Prudente, se qualifica como uma área de rastejo, por possuir velocidades baixas de deslizamento, sendo decrescentes com a profundidade, além de possuir movimentos constantes. Essa área se qualifica como R3 - Risco Alto, visto que se observa a presença de significativa instabilidade como trincas no solo, degraus de abatimento em taludes, e é possível a ocorrência de eventos destrutivos durante episódios de chuvas intensas e prolongadas.

O terceiro local está localizado na rua Altamiro Nunes Leite no bairro Vila Barreiros e se enquadra como uma área de tombamento, por possuir velocidades baixas de deslizamento, sendo decrescentes com a profundidade, além de possuir deslizamentos laterais na presença de chuvas. Essa área se qualifica como R2 - Risco Médio, pois observa-se a presença de evidências de instabilidade, necessitando de medidas de contenção adequadas. 


\section{Considerações Finais}

A partir das áreas analisadas obteve-se a classificação de risco R4 para a rua Godofredo Mollendorff no bairro Funcionários, risco R2 para a rua Altamiro Nunes Leite na junção dos bairros Vila Barreiros e classificação de risco R3 para a rua Presidente Prudente localizada no Bairro Jardim São Paulo.

Para ambos os casos são necessários medidas preventivas como a observação continua da área, a fim de inibir ou minimizar os impactos de possíveis movimentos de massa. Tal processo se daria por meio da observação de possíveis novas trincas e/ou evolução daquelas que já existem no local, auxiliado por documentação fotográfica, além da observação do abatimento do solo, verificação da movimentação de solo através da vegetação, e investigação de percolações de água.

Deste modo, podem-se minimizar ou impedir consequências indesejáveis a população local, como já ocorreu em outros momentos, como também para os órgãos superiores que poderão agir a fim de inibir a probabilidade de escorregamentos, caso haja, logo, as consequências seriam reduzidas e o impacto social, ambiental e econômico seriam amenizados.

O presente trabalho poderá contribuir para futuros estudos nas regiões que compõem Teófilo Otoni, como o mapeamento das demais áreas da cidade. A partir do exposto, esse estudo é de extrema valia na identificação e classificação de áreas de risco, visto que poderá ser utilizado pelos órgãos governamentais e sociais a fim de amenizar ou solucionar situações de risco à perda de vidas.

\section{Agradecimentos}

Agradecemos ao GEOVALES - Grupo de Pesquisas em Geociências e Engenharia dos Vales do Jequitinhonha e Mucuri, pelo apoio recebido na realização deste trabalho.

\section{Referências}

Almeida, L. Q. \& Carvalho, P. F. (2010). Representações, riscos e potencialidades de rios urbanos: análise de um (des) caso histórico. Caminhos de Geografia - Revista on line. Instituto de Geografia Ufu - Programa de Pós-graduação em Geografia, 11(34), 145-161.

Almeida, M. C. J. \& Freitas, C.G.L. (1996). Uso do solo urbano: suas relações com o meio físico e problemas decorrentes. In: Simpósio Brasileiro de Cartografia Geotécnica.

Andrade, I. L. (2015). Aplicação do modelo de zoneamento morfológico - funcional para o estudo do espaço intraurbano de cidades médias: análises da cidade de Viçosa - MG. Monografia. Departamento De Geografia - DGE. Universidade Federal de Viçosa. Novembro.

Augusto Filho, O. (1992). Caracterização geológico-geotécnica voltada à estabilização de encostas: uma proposta metodológica. In: Conferência Brasileira Sobre Estabilidade de Encostas, 1, 1992, Rio de Janeiro. Anais. Rio de Janeiro: ABMS/ABGE.

Batella, W. (2018). Estruturação urbana de Teófilo Otoni/MG: a topografia social de uma cidade média no Vale do Mucuri. Revista Caderno de Geografia, 28 (54), 793-811.

Bertone, P. \& Marinho, C. (2013). Gestão de riscos e resposta a desastres: a visão do planejamento. In: Congresso Consad de Gestão Pública, VI, Brasília. Brasília: CONSAD, p.1-22.

Brasil, Ministério das Cidades / Instituto de Pesquisa Tecnológica - IPT. (2007). Mapeamento de Riscos em Encostas e Margem de Rios. Brasília.

CPRM - Companhia de Pesquisa de Recursos Minerais. (1996). Serviço Geológico do Brasil. Projeto Leste: Folha SE 24 - V-CIV - Teófilo Otoni. Carta Geológica. Belo Horizonte.

CPRM - Companhia de Pesquisa de Recursos Minerais. (2015). Ação Emergencial para Delimitação de Áreas em Alto e Muito Alto Risco a Enchentes, Inundações e Movimentos de Massa. MG, Formiga. Serviço Geológico do Brasil.

Empresa Brasileira de Pesquisa Agropecuária - EMBRAPA. Sistema Brasileiro de Classificação de Solos. Brasília: Embrapa, DF. 5a edição. Revista e Ampliada. 2018.

Ferraz, L. M. C.; Valadão, C. R. \& Henrique, J. R. (2016). Geomorfologia do espaço urbano de Teófilo Otoni (MG): contribuições ao ordenamento territorial. In: XI SINAGEO. Geomorfologia: Compartimentação de paisagem, processo e dinâmica. Maringá - PR.

Gerscovich, D.M.S. (2007). Apostila Empuxo de terra Faculdade de Engenharia. UERJ, Departamento de Estruturas e Fundações. Rio de Janeiro. 
Research, Society and Development, v. 10, n. 15, e254101522754, 2021

(CC BY 4.0) | ISSN 2525-3409 | DOI: http://dx.doi.org/10.33448/rsd-v10i15.22754

Gomes, A. J. L., Silva, J. M. P., Gomes, J. L. S. \& Gomes, P. S. (2012). Gradiente Geotérmico do Município de Teófilo Otoni no Vale do Mucuri. Revista de Ciência e Tecnologia do Vale do Mucuri.

Gomes, A. J. L. (2020). Geological formations of the Mucuri river path in the State of Minas Gerais. International Journal of Geoscience, Engineering and Technology, 1 (1), 7-16.

Gomes, S. L. J; Gomes, L. J. A. \& Gomes, S. P. (2014). Planejamento Ambiental com base na geologia e sua aplicação no desenvolvimento urbano do munícipio de Teófilo Otoni. In: XI congresso nacional de meio ambiente de Poços de Caldas, Poços de Caldas - Minas Gerais.

IBGE - Instituto Brasileiro de Geografia e Estatística. (2018). População estimada. Diretoria de Pesquisas, Coordenação de População e Indicadores Sociais, Estimativas da população residente com data de referência $1^{\circ}$ de julho. IBGE.

IBGE - Instituto Brasileiro de Geografia e Estatística. (2019). Área da unidade territorial. Área territorial brasileira. Rio de Janeiro. IBGE.

Paul, C.; Kuhn, K.; Steinhoff, K., Bastian, W. \& Helming, K. (2020). Towards a standardization of soil-related ecosystem service assessments. European Journal of Soil Science.

Ramos, J. O. \& Gomes, A. J. L. (2016). Estratégias para Prevenção de Riscos Ambientais e Geológicos nos Espaços Urbanos da Cidade de Teófilo Otoni. Vozes dos Vales, V (9), 1-17.

Vargas, D. M. R. \& Cortés, F. R. (2009). Incorporando la gestión del riesgo de desastres en la planificación y gestión territorial. Guía técnica para la interpretación y aplicación del análisis de amenazas y riesgos. Lineamientos generales para la formulación de planes a nivel local. Proyecto Apoyo a la Prevención de Desastres en la Comunidad Andina - PREDECAN. Lima Perú.

Zêzere, J. L. (2005). Dinâmica de vertentes e riscos geomorfológicos. Centro de Estudos Geográficos. Lisboa: Universidade de Lisboa. 